\title{
Mechanisms of E-business Security and Enterprise Employee Voice Behavior Impacts on Team Creativity: A Cognitive Perspective
}

\author{
Shaozhong $\mathrm{Yu}^{1}$, Le Zhang ${ }^{1,2,3,}$ and Jinzhao Deng ${ }^{4}$ \\ ${ }^{1}$ College of Economics, Zhejiang University, Hangzhou, China, 310027 \\ ${ }^{2}$ School of Finance, Zhejiang University of Finance \& Economics, Hangzhou, \\ China, 310018 \\ ${ }^{3}$ China Academy of Financial Research, Zhejiang University of Finance \& \\ Economics, Hangzhou, China, 310018 \\ ${ }^{4}$ Economic and Management Department of Hunan University of Science and \\ Engineering, Yongzhou, China, 425100 \\ *zhangle@zufe.edu.cn
}

\begin{abstract}
With the development of E-commerce, more and more enterprises begin to use the network platform to carry on the sales; E-commerce transaction security will become the key issues and may restrict the development of electronic commerce. Using field survey method, this paper tried to explore the effects and internal mechanism of employee voice behavior in E-business Company. We collected data from provinces of Hubei, Hunan, Fujian, Guangdong and Zhejiang and got a sample of 93 multi-function work teams comprising 614 employees from E-business enterprises and institutions. All measurement instruments were adapted from well-established scales. Confirmatory factor analysis showed acceptable model fit indices. The values of inter-rated agreement and intra-class correlation indicated that the data aggregation from individual-level to shared team-level was reasonable, Through hierarchical regression and mediation and moderation effect analytic techniques the final results showed that voice behavior had a significant positive influence on team creativity. Team members' voice behavior has positive effect on team creativity was not only partially mediated by specialization and credibility dimensions of transactive memory system, but also fully mediated by team knowledge sharing. In addition, team learning behavior was found to have significant moderation effect on the relationship between voice behavior and team creativity.
\end{abstract}

Keywords: E-business security; team creativity; employee voice behavior; transactive memory system; knowledge sharing

\section{Introduction}

In the 21st century, knowledge economy becomes increasingly significant and makes creativity one of the key decisive factors of enterprise's survival and development. Competition between enterprises, to some extent, reflects competition of comprehensive creativity. Therefore, more and more enterprises begin to pay attention to their own innovation atmosphere and the cultivation of creativity. As Robert weaver once said "strategy researches of enterprises must give top priority to creative research, so that enterprises can have vitality". Nowadays, teamwork is common in various organizations, and team creativity has become a hot topic in academia and practitioners. Research has

*Corresponding Author (E-mail: zhangle@zufe.edu.cn) 
shown that creativity is not only closely related to the heterogeneous knowledge and information [1], but also interacts with situational atmosphere and interactions [2]. In face of the complex dynamic competitive environment, many companies build strategies through a variety of teams to improve and perfect the overall creativity.

In the past, researches on team creativity were primarily based on two theoretical perspectives. The first is formation perspective, i.e., team creativity is the accumulation of individual creativity, and individual creativity is the main factor of team creativity and is influenced by team environment [2]. Therefore team creativity is the average of those of team members [3].The second is overall perspective, namely, team creativity is the combination and coordination of individual creativity and has overall features. From this point of view, team creativity is the result of a series interactive process in a particular atmosphere and interactive behaviors which prompt members to realize the perspective "Epiphany type conversion" [4]. The overall perspective does not deny the role of individual creativity, but it emphasizes more on atmosphere characteristics and interactive process.

Although team creativity has important significance to the survival and development of enterprises, in reality, team creativity in real world management practices varies largely. Corresponding to the two theoretical perspectives, previous studies mainly explore and analyze from two aspects the formation of team creativity and its influencing factors: (1) The individual differences within team members, namely, individual personality, knowledge, skill and cognitive styles in the team will directly affect team creativity. For example, Kirton thinks individuals with innovative cognitive style have higher levels of creativity than those with adaptive cognitive styles. Therefore, the greater the percentage of such members in the team, the higher the level of creativity. Similarly, Vincent also thinks if team members have related knowledge, experience and skills of finding problems and creatively divergent thinking, the level of creativity in the team will be higher. (2) Team features (team cognition, Shared mental model, conflict level, etc.), team situation, communication and interaction will all invariably affect team creativity [2]. The logic explainer of this research angle is that: team members' individual creativity is important, but the team's overall creativity depends on the specific atmosphere, and communication and interaction among team members.

It is worth noting that knowledge heterogeneity, information acquisition, team interaction and cognitive system are important ways to explain differences in team creativity [5], which has more practical significance to management practice. Since it is common, in the construction of teams, to have management strategies such as helping team members get more heterogeneous information, encouraging deep communications among team members and building cooperative atmosphere. Research also suggest that team members take the initiative to put forward their own ideas, information and opinion expression actions - employees' suggestions have a positive effect on the quality of organizational decisions and knowledge transfers [6]. It is not hard to see that team with active employee voice behaviors have more comprehensive and rich knowledge information, and its creativity level is expected to be higher than other teams. Therefore, analyzing the influence of employees' behavior and team's cognitive perspective on team creativity will help better understand the deep formation mechanism of team creativity, provide basis for revealing its inner functional path and give has enlightenment function to team management practices. This research adopts real practice study and behaviorcognition-behavior logic line to explore the inner mechanism of employees' voice behaviors on team creativity. To be more specific, this study explores whether employee voice behavior influences team creativity through double paths of the implicit cognition team - trans active memory system (TMS) and the explicit cognition (knowledge sharing), and whether team learning behavior has a regulatory role during the process. 


\section{Literature Review and Hypothesis}

\subsection{Employee Voice Behavior and Team Creativity}

Employee voice behavior is a typical representative of employee initiative behavior research in recent years. Employee voice behavior means the employee voluntarily offers their comments or information towards the organization or the work. It is an orientation behavior that challenges status quo, is based on cooperation and innovation [7]. Different from general organization complaints or criticisms, employee voice behavior emphasizes the purpose of behavior, which is to improve the interests of the organization. Its behavior content may be new approaches, new ideas or new suggestions to promote the organizational efficiency. It can also be about problems in the current running organization or potential problems in the future [8]. Therefore, from the perspective of knowledge management, the essence of employee voice is information exchange and transmission based on comprehensive processing of self-perspective.

Relevant empirical studies show that employee voice behavior is closely related to performance results. In terms of subjective evaluation, Whiting (2008) found that, compared with employees who voice less, those who voice more get relatively high performance evaluations. This conclusion rapidly obtains extended validation in terms of objective performance evaluation. Jian Liang and Jing Tang (2009) studies on retail staff and found employee voice behavior has a positive effect on innovation performance [9]. Researches based on teams also found that voice behavior (criticism refers to formal recommendations and advocate pushing recommendations) has a positive effect on the innovation performance of technology innovation teams [10]. Edmondson thinks that the essences of this relationship are information communication, knowledge acquisition and interaction among team members, and thus produce new cognitions and actions.

During the teamwork, member voice behavior means giving own perspectives towards problems or weakness in the operation of the team. The expression of different ideas can stimulate moderate team cognitive conflict, and provide more cognitive material to the new editing knowledge and imaginary process [11]. More information related to work problems can promote divergent thinking of a team, and form team creativity cognition. Employee voice behavior, on the other hand, is individual behavior choice after weighing and its advising ways (such as choice of contingency uplink recommendations, considerate colleagues' voice or recommendations, and radical recommendations, etc.) help the two-way integration of information in the team, thus raising the possibility of mutual connection between various cognitive components. Innovative ideas and thoughts have great benefits for adaptation ability, environmental responses and innovation in the team [12]. Opposition ideas based on status quo make the team to have reflections, increase the flexibility and richness of cognition, and thereby promoting the formation of new ideas [13] and improving team creativity. Based on the above analysis, this study believes that in the teamwork, member voice behavior can have a positive impact on team creativity. Therefore, this study proposes the following assumptions:

Hypothesis1: team members' voice behavior has a significant positive effect on team creativity.

\subsection{Hidden Cognitive Path}

In studies on the team, cognitive structure gradually attracts the attention of scholars. Trans active memory system (TMS) represents the concept of team cognition and memory. The concept was put forward by Wegner (1987), and it described the cognitive structure of information distribution within team members who have different domain knowledge. Wegner defines it as a collaborative system in which team members interact to form a mutually dependent labor division system for coding, storage and acquisition. 
Through this system, team members understand each other's strengths. This system has benefit to enhance the effectiveness of the team to process information and communicate, maximize the value of knowledge of members [14]. Lewis (2003) thought transactive memory system could be measured through three aspects: the specialization and differentiation of knowledge, trust and reliance, coordination and mutual help [15]. Many previous studies not only verified the conception validity of transactive memory system, but also further explained the important role of this concept in team effectiveness mechanism [16].

Voice is a interpersonal communication behavior. In previous studies on transactive memory system, communication has been shown to have important effect on transactive memory system. The formation and maintaining of transactive memory system are implemented in the ongoing communication between team members [21]. Wenger (1995) defined the process: team members put forward ideas and suggestions many times from their own perspectives, making the team gradually form the distribution cognition of all kinds of knowledge, information and expertise [17]. When members understand strengths of individual members, they will new assign to the corresponding members the new problems or new knowledge. This practice will further strengthen the relatively stable cognitive dependencies.

Following the above logic, it is not difficult to find that voice behavior based on selfinsight of transactive memory system has various influences on team creativity. First of all, behavior researches that focus on the content think, ideas based on the individual professional thinking is an important starting point of voice behaviors. Team members put forward their own suggestions and countermeasures to solve the problem from their respective task areas. The heterogeneity of knowledge information's high frequency in the team not only effectively promote the accumulation knowledge and information and diversification, but also improve the absorption efficiency and utilization efficiency of knowledge information through the label of professional field, and thus providing multiple knowledge base for the ascension of team creativity. Secondly, many studies have shown that the premise of voice behavior is the safety perception and judgment towards team atmosphere by behaviors [18]. From another perspective, team members put forward their own suggestions and comments based on their confidence in the team and the positive expectations and the result of the recommendations. Active recommendations by team members are advantageous to the formation of open and trust atmosphere in the team [19]. Characteristic activation theory believes that, this atmosphere characteristic will further inspire the team members to voice, thus forming a mutually circulation of recommendations and trust. At the same time, the effectiveness of appropriate recommendations and voice (whether they have been adopted to take implementation or effect) is important clue and basis for team members to judge the reliability of the doer. The reliance of expertise reliability can improve the labor-division and cooperation efficiency in the process of task execution, not only making members find the source of information accurately and promptly, but also making them have deeper and more constructive exchanges and discussions, and thus producing more innovative solutions. Finally, positively pointing out problems in the team and their solutions can help other members have a clear understanding of what the adviser want, and, based on adviser's recommendation methods and content, choose the best mode of mutual cooperation. Member's voice behavior makes members have proper cooperation and coordination between members. A high level of interaction between members will greatly improve the possibility for different knowledge and information to collision and integrate, further activating team thinking and creating innovation. Based on the above analysis, this research believes that team member voice has an effect on team creativity through professionalism, credibility and coordination. Therefore, this paper has the following assumption: 
Hypothesis 2: the transactive memory system in the members' voice behavior and team creativity plays a mediating role relationship.

\subsection{Path of Dominant Role Cognition}

Some scholars pointed out that sharing ideas and opinions is an important mechanism to team creation process. The spread and sharing of individual's unique information or practice among members helps to improve team creativity [20]. The kernel of team knowledge sharing is the process of knowledge's understanding, transformation, absorption and utilization among members. Society with knowledge sharing character emphasizes the effects of social interaction during the process of knowledge receiving and diffusion. The cognitive view of knowledge sharing starts from the cognitive practice, paying attention to the creation of the cognitive environment and function. It believes that knowledge sharing, in using the existing knowledge, creates team knowledge; not only cognitive result is shared but also cognitive situation and interactive process are shared.

The vast majority of scholars believe that communication is the premise and guarantee to improve knowledge sharing within teams. Both Chinese and western culture background researches find important evidence that communication has a significant effect of knowledge sharing [21]. Since employee voice behavior is a spontaneous communication behavior; its communication content points the weaknesses of the team or organization, with the purpose to improve and perfect. Among factors that affect team knowledge sharing, employee voice behavior inevitably plays a significant role. It is reasonable to infer that employee voice has a positive effect on team knowledge sharing. The key premise to implement team knowledge sharing is that team members comprehensively and accurately understand knowledge, and employee voice creates opportunities for team members to exchange information and transfer knowledge. Any kind of voice form (written or oral, formal or informal, to individuals or to people, etc.) will constitute a media in information exchange within the team.

Previous researches regard employee voice as a role behavior, emphasizing on the prosocial (pro - social) features. It is this characteristic that makes employee voice's high frequency helps build trust and form a friendly emotional atmosphere. Pointed out solutions to problems or even giving specific suggestions not only lay a good foundation for cooperation between members. What is more important is that people who give voice share their unique ideas and information, create and spread team knowledge, creating a good condition for different knowledge to link together and cumulative innovation [22]. On the other hand, employee voice, in the corresponding solutions to specific problems, shares knowledge, and at the same time, through cognitive process such as explanation and interaction and the sharing of cognitive context among members, promotes the integration of diverse cognitive perspective and achieves cognitive development within team [23]. This is beneficial to fully dig out potential knowledge and promote the generation of new knowledge. Based on the above analysis, this study proposes the following hypothesis:

Hypothesis 3: knowledge sharing plays a mediating role in the relationship between employee voice and team creativity

\subsection{Adjustment Function in Team Learning Behaviors}

Team learning, as a constant reflection and action, has important effects on team creativity and therefore has received wide attention of scholars [24]. Team learning behaviors include raising and diagnosing problems, seeking feedback, reflecting strategies, trying new methods and improving, discussing errors or unplanned results. Team learning behavior, different from the concept such as team atmosphere and oriented share learning, emphases on the process of discussions and problem solving within team members. Team learning behavior depends on information searching and reconsideration 
of the decision making process. These processes provide team members with more valuable, abundant information and knowledge to build a more easy communication, relaxing, tolerant and lower risk of psychological environment. During teamwork, the equal cooperative relation-ship between members determines that the vertical position gap of members of is small. High team learning behavior makes communication between team members become more and more smooth and frequent. The reflection and discussion to the problem makes communication more direct, and such low situation communication conditions have a positive impact on the mutual understanding and cognition between team members and on the coordination in the working process, promoting the formation of the transactive memory system and the realization of the knowledge sharing; At the same time, high team learning behaviors encourage members, through communication, sharing and integration, understand teamwork knowledge and enhance expertise, laying foundation for new knowledge and new methods. Based on above analysis, this study proposes following assumptions:

Hypothesis 4a: team learning behaviors have an adjustment effect on the relationship between employee voice behavior and transactive memory system. The higher the team learning behaviors, the stronger the positive influence of employee voice behavior on transactive memory system, and thus creating a greater positive effect on team creativity.

Hypothesis 4b: team learning behaviors have an adjustment effect on the relationship between employee voice behavior and knowledge sharing. The higher the team learning behaviors, the more positive influence of employee voice behavior on knowledge sharing, and thus creating a greater positive effect on team creativity.

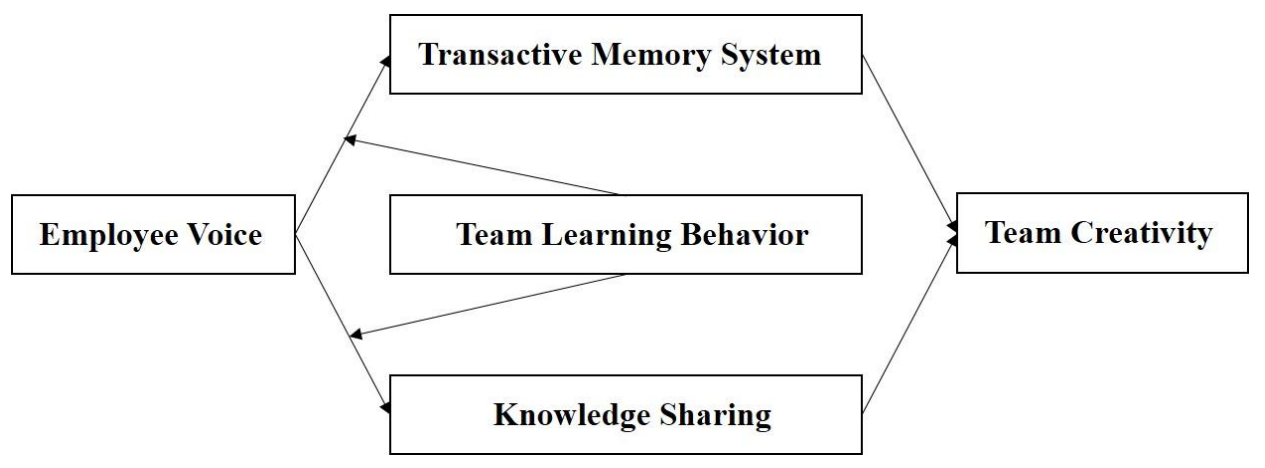

Figure 1. Research Framework

In conclusion, this study intends to explore the influence of employee voice behavior on team creativity function and its multipath mechanism based on cognition. The research framework is shown in Figure 1.

\section{Statistics and Methodology}

\subsection{Data and Sample}

Data were collected with questionnaire method (paper and electronic). The questionnaire is divided into two parts: basic information and scale sheet. The instructions require at least two-thirds of the group members or teams to participate. To eliminate the worries of the respondents, improve the ethical validity of the study and ensure that the respondents are involved in this study, all questionnaire papers are put into separate envelopes, indicating "this questionnaire is only used for scientific research, after completion, please put it back into the envelope and seal". Electronic questionnaires are sent via email to the contact company and the contact person sends questionnaires to the appropriate team. Electronic questionnaires have marked instructions and attention 
matters; after respondents complete it, the contact person collect the response and send to the writer. Just like paper questionnaire, questionnaires are all filled in anonymous form. After receiving questionnaires, we categorize them by the name of the team.

Research samples mainly come from E- business enterprises and institutions (including scientific research institutes and research centers in colleges and universities) in Hunan, Hubei, Fujian, Zhejiang and Guangdong and other regions. There are a total number of 800 questionnaires and 639 questionnaires are collected. After eliminating invalid, missing questionnaires and those do not conform to requirements (less than two-thirds of the team members answer the questionnaire), there are eventually 614 questionnaires from 93 working groups, with an effective recovery rate of $76.8 \%$. In the sample, 422 are men and 192 are women. Most teams come from enterprises (69 enterprise teams. Based on function, there are 28 from marketing, 8 from management, 16 from R\&D, 12 from production, and 5 from others. Nature of the enterprise is mainly private and joint ventures, including processing and manufacturing, garment, trade, finance, information and service industries; there are 24 scientific research institutions, including 13 from basic research, 8 from development and application, and 3 from others). The largest team size is 10 people, and the minimum is 3 people. The age distribution of the samples: 5 people are under the age of 20, 337 people are from 20 to 35 years old, 202 people are from 35 to 45 and 70 people are over the age of 45 . As for working years, 89 people have worked less than 3 years, 341 people 3 to 10 years and 184 people over 10 years. As for the participants' level of education, 110 people are under higher vocational college or below, 353 are college graduate or have bachelor degree, 151 people are graduate student (master and doctor degree (mainly in scientific research institutions). The average working year of the sample is 3.89 years.

\subsection{Measurement}

Since the research data mainly come from questionnaire survey method, the same respondent has provided information about the units of all variables of this research. There may be a common method bias (CMB), so homologous method mutation testing is needed to measure the data. This research adopts the methods proposed by Podsakoff and outraged (1986) to conduct CMB tests. The results of all factor variables have showed that the extraction of characteristic value is greater than 1 precipitation factor may explain the total variance reached $70.37 \%$, with the largest variance of factor accounting for $21.08 \%$ of the total variance. There is no single factor that has a variance accounting for the vast majority of covariance ratio. Therefore, variables in this research are unlikely to have human covariant, and the CMB common method of the sample data is not significant. Variables in this study include: employee behavior, transactive memory system, team knowledge sharing, team creativity, team learning behavior. Specific measurement tools are as follows:

The measurement of employee behavior were the measurement sheets created by Van Dyne \& LePine (1998), which have shown a relatively stable level of reliability and validity in many researches [25]. According to the requirements of team situation, this research only adjusts some pronouns in the original scale and makes translation comparisons. There are 6 questions in the scale, such as "team members give positive suggestions for team work and new project". This research uses a 5-point scale, i.e., from "1 - completely disagree" to "5 - totally agree".

In referring to the transactive memory system developed by Lewis (2003), combined with the scale of the localization research conclusion (mainly developmental work by Zhang Zhixue, etc. in 2006) [20], drawing lessons from past practices, this research has a 3 -scare measurement towards transactive memory system: expertise, credibility and coordination. There are 15 questions, such as "each member of the team has the related task knowledge". This research uses a 5-point scale, from "1 - don't conform to the" to "5 - completely in line with" evaluation. 
The measurement of team knowledge sharing is based on sharing of knowledge. It refers measurement tools by King \& JrMarks (2005) and Collins \& Smith (2006) and makes appropriate modifications. The measurement includes 5 questions, such as "team members in the professional team often have face-to-face discussion. This research uses a 5-point scale, from "1 - don't conform to the" to "5 - completely in line with" evaluation.

The measurement of team learning behavior uses tools developed by Edmondson (1999). There are 7 questions and 5 point scales from " 1 - don't conform to the" to "5 completely in line with" the evaluation. Since the original scale sheet is in English, this study, after Chinese translation, invites teachers with management psychology background to make a comparable analysis with the original scale and the Chinese version. It also asks for amendment suggestions to make the semantic difference in a minimum level. Questions include "team members often discuss the problem freely".

The measurement of team creativity mainly comes from Chen (2006), who sums up the scale of team creativity on the basis of Amabile research (the method emphasizes the interaction and influence of such factors as team atmosphere), and combined with findings by Neil and Michael (1998) [26]. This research selects 7 questions that best meet the needs of this study, such as "teams often adopt different methods to solve the problem". Likewise, the scale is 5 points, from "1 - don't conform to the" to "5 completely in line with" evaluation.

Control variables. Past researches think that the employees' level of education and work experience may influence the innovation performance of the team. At the same time, the current length of working time of members is closely associated with familiarity between team members, thus affecting the formation process of transactive memory system [22]. Control variables in this research include: education level (1 for higher vocational college and below, 2 for college degree, 3 for bachelor's degree, 4 for master's degree, 5 for doctoral degree), work experience (working time) and familiarity between team members (working years in the current team). The information is listed in the first part of the questionnaire and is average data is used to represent the level the team.

\subsection{Statistical Analysis}

This research uses SPSS18.0 and Amos7.0 software to conduct statistical analysis. Since the study analysis is based on teams, firstly all individual data are aggregated to the team level, and are tested the effectiveness according to the evaluators' evaluation consistency coefficient of RWG and ICC index. After testing the measurement model, mediating effect is tested. Finally, by estimating the direct effect and indirect effect, researches analyze the regulation effect of team learning behaviors.

\section{Empirical Analysis}

\subsection{Data Aggregation}

The data in this research come from the individual level and are needed to be aggregated into the team unit. Referring previous practices, this research adopts RWG and ICC index to analyze the effectiveness of the data structure. James (1984) thinks that if the team evaluators' evaluation consistency coefficient of RWG is greater than or equal to 0.7, the evaluation level of consistency in the project is acceptable. Calculation results show that the respective RWG variables are: the average employee voice behavior 0.846, team learning behavior 0.782 , transactive memory system 0.717 , knowledge sharing 0.768 , and team creativity 0.813 , and the proportion of RWG value which is greater than 0.7 minimum is $89.6 \%$, indicating that there is a consistent level of evaluation. At the same time, based on the correlation coefficient of evaluation standards (ICC1 is greater than the threshold, ICC2 is greater than the critical value 0.60 .12 ), the corresponding variable values are: employee voice behavior ICC1 0.182 and ICC2 0.915 , team learning 
behavior ICC1 0.203 ICC20.883, and ICC2 transactive memory system ICC1for 0.144 to 0.741 , the knowledge sharing ICC1 and ICC2 for 0.232 to 0.691 , team creativity ICC1 0.192 ICC2 0.192. Variance analysis has showed that there exist significant differences in the mean square between groups and within groups. Based on the above analysis, aggregating individual data to the team data is feasible and effective.

\subsection{Scale Sheet's Reliability, Test Validity and Results of Descriptive Statistics of Variables}

The results of exploratory factor analysis have shown that, the third and seventh questions have a low load ( 0.414 and 0.481 respectively). Alpha consistency coefficient calculation found that after deleting these questions, team learning behavior overall reliability significantly increased from 0.723 to 0.723 . After the correlation coefficient analysis, the scale finally keeps five questions, with factors explaining $76.3 \%$ of the total variance. The second question in the Team creativity belongs to the fuzzy and lower load (0.382), and after eliminating the question, the scale improves the overall reliability (alpha coefficient increased from 0.822 to 0.822 ), in the subsequent studies included in the analysis of the scale, there are only six question, with factors explaining $80.65 \%$ of the total variance. As for the measurement results of transactive memory system, exploratory factor analysis precipitation gives three factors, largely in line with the dimensions define the connotation of the original scale. But question 2 and 6 have loads averagely in all factors and factor belonging is not obvious. Question 9, 10, 13, 15 have small load, and through correlation analysis and comparison, question 2, 10,13,15 are deleted. After deleting, the reliability level of scale rises from 0.773 to 0.773 and 11 questions are included in the end into the analysis of the questionnaire (expertise 4 questions, credibility 4 questions and coordination 3 questions), with factors explaining $69.1 \%$ of the total variance. The final scale of reliability coefficient test results is shown in table 2.

This research uses confirmatory factor analysis (CFA) method to analyze data and examine the five variables (employee voice behavior, transactive memory system, knowledge sharing, team learning behavior and team creativity) to illustrate the identify validity of measurement. The analysis results are shown in Table 1.

Table 1. Results of CFA

\begin{tabular}{|c|c|c|c|c|}
\hline Model & Chi-square/df & NFI & CFI & RMSER \\
\hline Single factor model & 8.875 & 0.678 & 0.713 & 0.195 \\
\hline Two factors model & 5.113 & 0.724 & 0.774 & 0.171 \\
\hline Three factors model & 4.787 & 0.805 & 0.837 & 0.134 \\
\hline Four factors model & 4.183 & 0.862 & 0.872 & 0.106 \\
\hline Five factors model & 3.711 & 0.881 & 0.892 & 0.094 \\
\hline
\end{tabular}

Note: Single factor model: employee voice behavior+ transactive memory system team learning behavior+ knowledge sharing + team creativity; Two factors model : employee voice behavior + transactive memory system + team learning behavior+ knowledge sharing; Three factors model: employee voice behavior + team learning behavior; Transactive memory system + knowledge sharing; Four factors model: transactive memory system + knowledge sharing

From Table 1, the indexes of 5-variable model has reached the recommended model, with all measurements above other models, indicate that measurements have acceptable recognition degree. Table 2 shows the descriptive results of all variables, including mean, standard deviation, correlation coefficient matrix and coefficient of aconfident level. 
Table 2. Means, Standard Deviations and Correlations

\begin{tabular}{|c|c|c|c|c|c|c|c|c|c|c|}
\hline Variable & Mean & SDANN & 1 & 2 & 3 & 4 & 5 & 6 & 7 & 8 \\
\hline 1 Education level & 3.722 & 0.881 & - & & & & & & & \\
\hline 2 Years of working & 4.591 & 2.880 & 0.041 & - & & & & & & \\
\hline 3 Curr. team YOW & 3.894 & 0.414 & 0.145 & 0.093 & - & & & & & \\
\hline 4 Employee suggest & 3.882 & 0.501 & $0.490^{* *}$ & -0.165 & -0.183 & $(0.922)$ & & & & \\
\hline 5 Tr. memory sys. & 3.573 & 0.177 & 0.154 & -0.152 & $0.528^{* *}$ & $0.266^{*}$ & $(0.804)$ & & & \\
\hline 6 Kowledge sharing & 3.665 & 0.401 & $0.517^{* *}$ & $-0.201^{*}$ & 0.091 & $0.566^{* *}$ & $0.242^{*}$ & $(0.771)$ & & \\
\hline 7 Team learning & 3.489 & 0.238 & $0.477^{* *}$ & -0.122 & 0.110 & $0.475^{* *}$ & $0.457^{* *}$ & $0.536^{* *}$ & $(0.767)$ & \\
\hline 8 Team creativity & 3.406 & 0.463 & $0.425^{* *}$ & $-0.223^{*}$ & 0.104 & $0.362^{* *}$ & $0.334^{* *}$ & $0.528^{* *}$ & $0.518^{* *}(0.886)$ \\
\hline
\end{tabular}

The results of descriptive statistical analysis in Table 2 show that, consistent with the theoretical expectations, employee voice behavior is significantly correlated with transactive memory system, knowledge sharing and team creativity. Transactive memory system is also significantly correlated with knowledge sharing and team creativity, providing premise and basis for the relationship analysis between variables and the validation test of mediation effect. At the same time, the correlation coefficient between employee voice behavior and team creativity is $0.362(\mathrm{p}<0.01)$, therefore hypothesis 1 is confirmed to some degree.

\subsection{Hypothesis Test}

The mediation effect of transactive memory system. Firstly, control variables are included into the regression equation (M0), then the following regression model is built respectively: employee voice behavior is the independent variables, transactive memory system is the dependent variable (M1), transactive memory system is the independent variable, team creativity is the dependent variable (M2), employee voice behavior is the independent variables, and team creativity is the dependent variable (M3). Finally, based on regression results of the four models, build a model with employee voice behavior and transactive memory systems as independent variables at the same time, and team creativity as the dependent variable (M4) model. The results of the regression analysis are shown in Table 3.

Table 3. Results of Regression Analysis on Mediating Effect of TMS

\begin{tabular}{|c|c|c|c|c|c|}
\hline VARIABLE & M0 & M1 & M2 & M3 & M4 \\
\hline Control variable & & & & & \\
\hline Educational level & 0.014 & 0.127 & 0.029 & 0.213 & 0.012 \\
\hline Years of working & 0.094 & -0.123 & -0.118 & -0.113 & -0.077 \\
\hline Current team YOW & -0.172 & $0.204^{*}$ & -0.076 & 0.173 & 0.021 \\
\hline Argument & & & & & \\
\hline Employee suggest & & $0.203^{*}$ & & $0.366^{* *}$ & $0.263^{*}$ \\
\hline Metavariable & & & & & \\
\hline TMS & & & $0.348^{* *}$ & & $0.31^{* *}$ \\
\hline R2 & 0.042 & 0.307 & 0.133 & 0.174 & 0.215 \\
\hline$\triangle \mathrm{R} 2$ & & & & & 0.041 \\
\hline $\mathrm{F}$ & 1.317 & $11.442^{* *}$ & $3.147^{*}$ & $4.406^{* *}$ & $4.686^{* *}$ \\
\hline
\end{tabular}

Note: $\mathrm{N}=93 ; * * \mathrm{p}<0.01, \mathrm{p}<0.01,+\mathrm{p}<0.5$; Beta is a standard coefficient.

It can be seen from table 3 that, control variables in this study barely have main effects. Model 3 shows that employee voice behavior contributes to 0.366 of team creativity ( $\mathrm{p}$ 0.01 ), and variation can be explained is $17.4 \%$, indicating employee voice behavior has a significant positive effect on team creativity and hypothesis 1 is confirmed. Based on the regression results of model M1, M2, and M3, the three conditions to judge the mediation effect of transactive memory system are met. Employee voice behavior and transactive 
memory system are into the regression equation to get model 4 , and results have showed that after adding intervening variables, the regression coefficients of employee voice behavior decline (beta $=0.366, \mathrm{p}<0.01$ down to $0.263, \mathrm{p}<0.05$ ), the equation of determination coefficient R2 increases from 0.17 to 0.17 and the increase of R2 is 0.04 . In statistical aspect, it achieves a significant level $(\mathrm{p}<0.01)$. Judging from the inspection criterion of intermediary effect, transactive memory partly mediates relationship between employee voice behavior and team creativity. Hypothesis 2 is supported by data.

To find the intermediary path that employee voice behavior's effect has on team creativity, the research processes according to the above steps and three dimensions of transactive memory system are included into the regression equation. Results have shown that the coordination in the M2 has no significant effects on team creativity (beta $=0.030$, $p=0.787)$, expertise and credibility have regression coefficients of $0.204(p<0.05)$ and 0.233 ( $p<0.05$ ). After all variables are added into the regression equation, coordination's regression coefficient is not significant (beta $0.01, \mathrm{p}=0.932$ ), expertise and credible regression coefficients are $0.191(\mathrm{p}=0.06)$ and $0.202(\mathrm{p}=0.04)$. The regression coefficient of employee voice behavior of decreases from $0.368(\mathrm{p}<0.01), 0.368$ ( $<<$ 0.05 ), $\mathrm{R} 2$ increases from 0.265 to 0.265 (delta $\mathrm{R} 2=0.023, \mathrm{p}<0.01$ ), suggesting that the transactive memory system of expertise and credible intermediary staff voice behavior on team creativity. The intermediary effect of knowledge sharing. Based on the above analysis, intermediary effect of knowledge sharing is tested. The analysis results are shown in Table 4.

Table 4 shows the results of regression analysis: when employee voice behavior and team knowledge sharing are included into the equation, the regression coefficient of knowledge sharing is significantly (beta $=0.48, \mathrm{p}<0.01$ ), but the coefficient of employee voice behavior under the regression declines significantly from 0.37 to -0.29 , and doesn't pass the significance test. Overall variation explanation increases from $17 \%$ to $35 \%$, R2's increment is 0.18 , and is significant at the 0.01 level. Therefore, we can determine that knowledge sharing fully mediates the relationship between employee voice behavior and team creativity, and thus hypothesis 3 is supported by empirical data.

Table 4. Results of Regression Analysis Mediating on Effect of KS

\begin{tabular}{|c|c|c|c|c|c|}
\hline VARIABLE & M0 & M1 & M2 & M3 & M4 \\
\hline Control variable & & & & & \\
\hline Educational level & 0.013 & -0.128 & $0.237^{*}$ & 0.214 & 0.166 \\
\hline Years of working & 0.104 & -0.121 & -0.088 & -0.105 & -0.065 \\
\hline Current team YOW & -0.165 & 0.095 & 0.164 & 0.173 & 0.155 \\
\hline Argument & & & & & \\
\hline Employee suggest & & $0.596^{* *}$ & & $0.368^{* *}$ & -0.288 \\
\hline Metavariable & & & & & \\
\hline Team knowledge sharing & & & $0.375^{* *}$ & & $0.476^{* *}$ \\
\hline $\mathrm{R} 2$ & 0.043 & 0.357 & 0.312 & 0.172 & 0.354 \\
\hline$\Delta \mathrm{R} 2$ & & & & & 0.182 \\
\hline $\mathrm{F}$ & 1.323 & $14.096^{* *}$ & $11.455^{* *}$ & $4.414^{* *}$ & $10.793^{* *}$ \\
\hline
\end{tabular}

Note: $\mathrm{N}=93 ; * * \mathrm{p}<0.01, \mathrm{p}<0.01,+\mathrm{p}<0.5$; Beta is a standard coefficient.

Regulating effect test: To test hypothesis $4 \mathrm{a}$ and $4 \mathrm{~b}$, this study refers views of Edwards, combines testing methods and steps with intermediary effect put forward by Zhonglin Wen (2006) [27], makes team creativity as one of the variables and therefore the following regression equation is set up respectively: (1) team learning behavior regulation effect test that is the mediated with transactive memory system: make team creativity as outcome variable, employee voice behavior, team learning behavior and employee voice behavior * team learning behavior as independent variables (MT1), transactive memory system as the result variable 2, employee voice, team learning behavior and employee voice behavior * team learning behavior as the independent variable $\mathrm{x}$ team learning behavior model (MT2), team creativity as the result variable, employee voice, team 
learning behavior, employee voice behavior by team learning behavior and transactive memory system as independent variables (MT3); (2) regulatory effect test that is mediated with knowledge sharing: make knowledge sharing as outcome variable, employee voice behavior, team learning behavior and employee voice behavior * team learning behavior as independent variables (MK2) 3. We make team creativity as outcome variable, employee voice behavior, team learning behavior, employee voice behavior $*$ team learning behavior and the knowledge sharing as the independent variable (MK3). The regression analysis results are shown in Table 5.

Table 5. Results of Regression Analysis on Moderation Effect of TLB

\begin{tabular}{|c|c|c|c|c|c|}
\hline VARIABLE & MT1 & MT2 & MT3 & MK2 & MK3 \\
\hline Educational level & -0.137 & 0.133 & -0.152 & -0.267 & -0.078 \\
\hline Years of working & -0.088 & -0.091 & -0.087 & -0.085 & -0.073 \\
\hline Current team YOW & 0.134 & -0.255 & 0.091 & 0.033 & 0.117 \\
\hline Employee suggest & $0.312+$ & $0.316+$ & 0.293 & $0.588^{* *}$ & 0.283 \\
\hline Team learning behavior & $0.406^{* *}$ & $0.477^{* *}$ & 0.213 & $0.365^{* *}$ & $0.282^{*}$ \\
\hline Employee suggest+ TLB & $0.434^{*}$ & $0.347^{* *}$ & $0.414+$ & $0.282^{*}$ & $0.528^{* *}$ \\
\hline TMS & & & $0.377^{* *}$ & & \\
\hline Knowledge sharing & & & & & $0.355^{* *}$ \\
\hline $\mathrm{R} 2$ & 0.315 & 0.408 & 0.366 & 0.456 & 0.425 \\
\hline$\Delta \mathrm{R} 2$ & & 0.093 & 0.051 & 0.141 & 0.110 \\
\hline $\mathrm{F}$ & $8.201^{* *}$ & $11.343^{* *}$ & $7.516^{* *}$ & $14.487^{* *}$ & $9.071^{* *}$ \\
\hline
\end{tabular}

In the Table 5 MT1 model, the regression coefficient of employee voice behavior * team learning behavior passes the significance test (beta $=0.434, \mathrm{p}<0.01$ ), suggesting the team learning behavior has a positive direct adjustment effect. The regression coefficients in the MT2 model of employee voice behavior * team learning behavior is also significant (beta $=0.347, \mathrm{p}<0.01$ ). Combing the results of model M2 in Table 3 (beta $=0.35, \mathrm{p}<$ 0.01 ), we can see that the team learning behavior is an intermediary variable and in addition to the direct regulating effect, team learning behavior, through transactive memory system, also has an indirect regulating effect on team creativity; Model MT3 shows that the coefficient of transactive memory system is significant (beta $=0.377, p<$ 0.01 ), and the product of regression coefficients is significant at the 0.1 level (beta $=$ $0.414, \mathrm{p}<0.1$ ), indicating that the regulatory effect partly takes effect through transactive memory system. Hypothesis 4 is also confirmed. Combing the results of MK2 model in table 5 and model M2 in Table 4 (in Table 5 the regression coefficient of the product item in MK2 model is $0.28, \mathrm{p}<0.05$, in table 4 model in M2 model is $0.38, \mathrm{p}<0.01$;). We can see that team learning behavior has an intermediary regulatory effect, and in addition to direct regulating effect, team learning behavior has indirect regulating effect on team creativity through knowledge sharing; in the MK3 model, the regression coefficient of the product item is $0.528(\mathrm{p}<0.01)$ and the coefficient of knowledge sharing (beta $=0.355$ ) is significant at the 0.01 level, indicating that team learning behavior takes regulatory effect on team creativity partly through knowledge sharing. Hypothesis $4 \mathrm{~b}$ is supported.

\section{Discussion}

In recent years, researches of the academia on team creativity gradually break through the observable behavior representation perspective, and form a new research perspective based on implicit cognition. This kind of perspective tries to explain the formation process and mechanism of team creativity from the understanding and sharing of groups, interaction and coordination [28]. Based on the logic line of behavior-cognitiveefficiency, this study explores a common organizational behavior-the inner mechanism of employee voice behavior on team creativity, and studies the regulatory effect of team learning behavior during process. 


\subsection{Discussion of the Results}

The influence of employee voice behavior on team creativity: The results of this study have shown that the employee voice behavior has a positive effect on team creativity, confirming that encouraging employees to make suggestions is a meaningful management strategy. In fact, although employee voice behavior has caused wide attention of scholars both home and abroad in recent years, most of the researches focus on the influence factors and mechanism of the behavior. Few researchers pay attention to the behavior consequences (even though in management practices there have been practices to think together). Returning to the nature of creativity, knowledge information is indispensable to creative creativity [5] and related studies on knowledge management have shown that multi-perspective views, heterogeneous knowledge and information can arose mental agitate and promote creativity. This research, from the angle of behaviorism, again verifies it. Its internal logic is that: employee voice behavior provides diverse information and ideas for the team, promotes mutual learning and integration of skills, and the spread of the best practices within the team.

The intermediary effect of team cognition: This study, from the angle of cognition, explores the inner mechanism of employee voice behavior on team creativity. The results have shown that transactive memory system and knowledge sharing have remarkable intermediary effect in the relationship between employee voice behavior and team creativity, providing new empirical evidence to explain the cognitive mechanism of team creativity. This study has found that employee voice behavior takes effects on team creativity by expertise in the transactive memory system and reliability, and that the intermediary effect of coordination dimension is not significant. One possible reason is that as a special kind of team communication, voice provides basis for others to judge the advisers' knowledge and expertise, makes it possible for team members to understand each other's knowledge and the proper distribution of information responsibility; what's more, advising itself is helpful to establish social networks based on friendship or familiarity -- the important characteristics of the network are interdependence and trust [29]. Employee voice behavior, on the other hand, takes effects on team creativity through knowledge sharing and this finding, to a certain extent, deepens our understanding of the relation between behavior and team effectiveness. Previous studies suggest that the key in team creativity is to obtain and integrate team members with unique knowledge, information and power [30]. Employee voice behavior created the condition for the depth of knowledge sharing and information processing for the team. It should be pointed out that, employee voice behavior itself is an active idea-sharing behavior. It meets the basic requirements of knowledge sharing and can help the sharing of cognitive situation and cognitive result within the team. At the same time, high frequency of employee voice behavior in the team increases the mutual understanding among members, with increased expertise, trust and coordination, thus forming a more mature latent cognitive structure-the transactive memory system. Therefore, the role of employee voice behavior is mainly achieved through two kinds of cognitive mechanisms; first is the explicit cognitionknowledge sharing, and the second is the implicit cognition - transactive memory system.

The regulatory effect of team learning behavior: Applying hierarchical regression method, this research explores the regulatory effect of team learning behavior on the relationship between employee voice behavior and team creativity. Consistent with the theoretical expectation, this study found that in the relationship between employee voice behavior and team creativity, team learning behavior's direct regulatory effect and indirect regulatory effect are both significant. In the intermediary chain of employee voice behavior - transactive memory system - team creativity, the higher the frequency of team learning behavior, the stronger the positive relationship between transactive memory system and employee voice behavior, therefore creating more positive effects on team creativity; In the intermediary chain of employee voice behavior - knowledge sharing - 
team creativity - team creativity, the high frequency of team learning behavior makes employee voice behavior has a more positive role in promoting knowledge sharing, and thus creating more favorable impact on team creativity. The study also found in the above two intermediary chains, the regulatory influence of team learning behavior takes effect through intermediary variables (knowledge sharing and transactive memory system). Some scholars believe that social information source provided for the individual by team learning behavior is an external motivation of members' social learning, and as a result, it encourages information searching and sharing reflection results, therefore creating an important influence on team performance. Domestic longitudinal tracking study also shows that team learning behavior takes effect on team performance through transactive memory system [22]. This research, from the angle of team situational characteristic, verifies that team learning behavior has an important influence on team creativity, and this is study supports former related research conclusions.

\subsection{Theoretical and Practical Significance}

This study is based on the organizational situations in China and discusses the inner mechanism and conditions of employee voice behavior on team creativity. This research has some beneficial enlightenment to both theory and practice. In theoretical contributions, of the relevant researches in the field of employee voice behavior, most scholars discuss the influence factors and mechanism of the behavior. This study further assumes and verifies the positive effect of employee voice behavior on team creativity, and provides evidence of the value of the role to external behaviors; At the same time the research reveals the cognition mechanism of employee voice behavior on team creativity and further confirms the important role of team learning behavior in the process of employee voice behavior on team creativity. Besides, this study provides new evidence for the theory of team process and team functions; finally, this research, from the perspective of the development process of "behavior-cognitive-status", explores the formation mechanism of team creativity, and lays a foundation to understand the relationship between the specific behaviors and their results.

The management reference and practical significance of this research is that: When an open channel of rationalization proposal is built and voice by employees is encouraged, at the same time, companies should promote the communication between team members to achieve sharing of knowledge and information, build an atmosphere conducive to team learning, pay attention to the feedback and reflection during teamwork process. Companies should make sure the deepening of each team member's expertise and the interdependent relationship between team members.

\subsection{Research Limitations and Prospects}

The limitations of this study mainly reflect in: (1) measurement problem. This study uses the questionnaire method to measurement group levels, and there may have be some deviations between measurement results and the actual cognitive levels. Meanwhile, employee voice behavior level is self-reported, so that will probably be affected by the wide effect. In addition, the research sample is based on the principle of convenience sampling, with samples from different geographical areas being relatively small. The final team sample size is 93, which has insufficient representativeness, so that the generalization of the results needed to be more concise. In view of this, the future research should enlarge the sample size, measure as many data as possible, integrate information from many aspects of data to get more accurate measurement results; (2) research design. This study uses cross-sectional data to infer causal relationships and this may affect the overall validity of the study. Since, from the employee voice behavior to the understanding of each member's knowledge, absorption, formation of implicit cognitive structure, and thee generation of new knowledge in the team, necessary time effect is 
contained. Therefore, future researches may consider adopting longitudinal research design, collecting relevant data respectively at different time points to strengthen the causal inference of theory hypothesis.

\section{Conclusion}

This study, through field investigation, has shown that employee voice behavior has a significant positive effect on team creativity. Transactive memory system has a partial intermediary effect on employee voice behavior and team creativity-specifically, employee voice behavior mainly effect on team creativity through expertise and trust parts in transactive memory system. Knowledge sharing has a fully intermediary effect on employee voice behavior and team creativity; Team learning behavior has a significant positive regulatory effect on the relationship between employee voice behavior and team creativity.

\section{Acknowledgments}

The authors are grateful for research support from MOE (Ministry of Education in China) Project of Humanities and Social Sciences (Grant No. 14YJC790167), Scientific Research Staring Foundation for the Returned Overseas Chinese Scholars Ministry of Education of China (Grant No. (2013)1792), Project of Educational Commission of Zhejiang Province in China (Grant No. Y201432409) and Ministry of Education, Humanities and Social Sciences General Project (Grant No. 12YJA630022).

\section{References}

[1] M. H. Chen, Y. C. Chang and S. C. Hung, "Social Capital and Creativity in R\&D Project Teams", R\&D Management, vol. 39, (2009), pp. 21-33.

[2] S. Taggar, "Individual Creativity and Group Ability to Utilize Individual Creative Resources: A Multilevel Model”, Academy of Management Journal, vol. 45, (2002), pp. 315-330.

[3] A. Pirola-Merlo and L. Mann, "The Relationship between Individual Creativity and Team Creativity: Aggregating across People and Time”, Journal of Organizational Behavior, vol. 25, (2004), pp. 235-257.

[4] M. Barlow, "Deliberate Insight in Team Creativity", Journal of Creative Behavior, vol. 34, (2000), pp. 101-117.

[5] M. A. Davis, "Understanding the Relationship between Mood and Creativity: a Meta-analysis", Organizational Behavior and Human Decision Processes, vol. 108, (2009), pp. 25-38.

[6] B. Gongxian and Q. Yuanyuan, "Extra-role Behavior and Team Creativity Performance: a Multiperspective Study", Journal of Zhejiang University (Humanities and Social Sciences), vol. 39, (2009), pp. 113-122.

[7] L. VanDyne, S. Ang and I. C. Botero, "Conceptualizing Employee Silence and Employee Voice as Multidimensional Constructs", Journal of Management Studies, vol. 40, (2003), pp. 1359-1392.

[8] J. Liang and J. L. Farh, "Promotive and Prohibitive Voice Behavior in Organizations: A two-wave Longitudinal Examination", Third Conference of the International Association for Chinese Management Research, Guangzhou, (2008).

[9] L. Jian and T. Jing, "A Multi-level Analysis of Employee's Proper Voice: Evidence from Local Chain Supermarket", Nankai Business Review, vol. 12, (2009), pp. 125-134.

[10] Q. Yuanyuan, "Mechanisms of Employee Loyalty, Extra-role Behavior and Team Creativity Performance: a Multi-perspective Study", Zhejiang University, (2010).

[11] M. Reinbolt, T. Pedesen and N. J. Foss, "Why a Central Network Position isn't enough: the Role of Motivation and Ability for Knowledge Sharing in Employee Networks", Academy of Management Journal, vol. 54, (2011), pp. 1277-1297.

[12] J. Rank, V. L. Pace and M. Frese "Three Avenues for Future Research on Creativity, Innovation, and Initiative”, Applied Psychology: An International Review, vol. 53, (2004), pp. 518-528.

[13] C. K. DeDreu, "When too little or too much hurts: Evidence for a Curvilinear Relationship between Task Conflict and Innovation in Teams", Journal of Management, vol. 32, (2006), pp. 83-107.

[14] Z. Zhixue, S. H. Paul, H. Yulan and Q. Jing, "Transactive Memory System and Its Effects in High-tech Teams", Acta Psychologica Sinica, vol. 38, (2006), pp. 271-280.

[15] K. Lewis, "Measuring Transactive Memory Systems in the Field: Scale Development and Validation", Journal of Applied Psychology, vol. 88, (2003), pp. 587-604. 
[16] W. Yanyi and P. Can, "The Influence of Informal Network on R\&D Team Performance: An Empirical Study with Transactive Memory System as an Intermediate Variable", Scientific Research, vol. 30, (2012), pp. 581-590.

[17] D. M. Wegner, “A Computer Network Model of Human Transactive Memory", Social Cognition, vol. 13, (1995), pp. 319-339.

[18] D. Jinyun, "The Influence of Paternalistic Leadership on Employee Voice Behavior: Intermediate Mechanism of Psychological Sense of Safety. Business Review, vol. 24, (2012), pp. 109-117.

[19] J. De and B. A., Elfring, "How Does Trust Affect the Performance of Ongoing Teams? the Mediating Role of Reflexivity, Monitoring, and Effort", Academy of Management Journal, vol. 53, (2010), pp. 535-549.

[20] T. Chaoying, A. Shu and G. Zengliang, "Positive Emotion's Social Functions and Influence on Team Creativity: the Intermediate Influence of Implicit Knowledge Sharing”, Nankai Business Review, vol. 14, (2011), pp. 129-137.

[21] L. Lin and L. Xueling, "The Intermediate Influence of Knowledge Sharing between Interpersonal Communication and Creativity", Nankai Business Review, vol. 12, (2009), pp. 118-123.

[22] P. M. Madsen and V. Desai, "Failing to Learn? the Effects of Failure and Success on Organizational Learning in the Global Orbital Launch Vehicle Industry", Academy of Management Journal, vol. 53, (2010), pp. 451-476.

[23] C. J. Collins and K. G. Smith, "Knowledge Exchange and Combination: the Role of Human Resource Practices in the Performance of High-technology Firms", Academic of Management Journal, vol. 49, (2006), pp. 544-560.

[24] G. Hirst, D. V. Knippenberg and J. A. Zhou, "Cross-level Perspective on Employee Creativity: Goal Orientation, Team Learning Behavior, and Individual Creativity", Academy of Management Journal, vol. 52, (2009), pp. 280-293.

[25] D. Jinzhao, "The Relationship between Team Member's Target Orientation and Voice Behavior: a Multi-level Analysis", Nankai Business Review, vol. 13, (2010), pp. 12-21.

[26] E. Neil and A. W. Michael, "Measuring Climate for Work Group Innovation: Development and Validation of the Team Climate Inventory: Summary", Journal of Organizational Behavior, vol. 19, (1998), pp. 235-259.

[27] W. Zhonglin, Z. Lei and H. Jietai, "Regulatory Variable with Intermediate Agent and Intermediate Variable with Regulation”, Acta Psychologica Sinica, vol. 38, (2006), pp. 448-452.

[28] B. Stefania, "Organizational Creativity: Breaking Equilibrium and Order to Innovate", Journal of Knowledge Management, vol. 9, (2005), pp. 19-33.

[29] L. A. DeChurch, "The Cognitive Underpinnings of Effective Teamwork: a Meta-analysis", Journal of Applied Psychology, vol. 95, (2010), pp. 32-53.

[30] J. S. Mueller, "Why Individuals in Larger Teams Perform Worse", Organizational Behavior and Human Decision Processes, vol. 117, (2012), pp. 111-124. 